\title{
Análise de programas estruturadores de saúde do Estado de Minas Gerais por meio de indicadores finalísticos
}

Geovana Maria Carmo Santos

Fundação João Pinheiro (FJP)

Mauro César Silveira

Fundação João Pinheiro (FJP)

Andre Correa de Oliveira

Fundação João Pinheiro (FJP)

O presente artigo visa analisar a relação entre o gasto nos programas estruturadores da área de saúde, do Governo de Minas Gerais, com os indicadores finalísticos da referida área, entre os anos de 2004 a 2013. Este estudo justifica-se pela possibilidade de se sinalizar a efetividade da alocação de recursos orçamentários, no âmbito da saúde, em face do modelo de Gestão para Resultados adotado pelo governo do estado. Os resultados encontrados sugerem uma forte correlação entre as variáveis, a despeito de três correlações consideradas não significativas, pelos cálculos estatísticos, e de uma das correlações que sinalizou uma relação contrária ao esperado. A análise de regressão confirmou a relação linear entre as variáveis, para os casos que se comportaram conforme a hipótese deste trabalho. A partir das entrevistas realizadas com dois gestores estaduais, apreende-se que, embora os indicadores não influam diretamente sobre a alocação de recursos, estes orientam o processo de implementação das políticas, sob uma perspectiva de priorização, e consistem, também, em importantes mecanismos para aperfeiçoamento do processo de gestão.

Palavras-chave: administração estadual, avaliação de políticas públicas, administração por objetivos, indicador de desempenho, gestão orçamentária e financeira

[Artigo recebido em 23 de janeiro de 2015. Aprovado em 2 de agosto de 2016.] 
Análisis de programas estructuradores de salud del Estado de Minas Gerais por medio de indicadores finalísticos

Este artículo tiene como objetivo analizar la relación entre el gasto en programas de estructuración de la Salud, en el gobierno de Minas Gerais, com Indicadores Finalísticos esa zona. Este estudio se justifica por la posibilidad de señalar la eficacia de la asignación de los recursos presupuestarios de la Salud, teniendo en cuenta el modelo de Gestión por Resultados adoptadas por el gobierno del estado. Los resultados sugieren una fuerte correlación entre las variables, apesar de que no se considere tres correlaciones significativas por cálculos estadísticos, y una correlacion, que marcó una relación opuesta a la esperada. El análisis de regresión confirmou una relación lineal entre las variables, para los casos que se han comportado de acuerdo con la hipótesis de este trabajo. A partir de entrevistas con dos gestores estatales, uno aprende que si bien los indicadores no influyen directamente em la asignación de recursos, que guian el proceso de implementación de la política bajo una perspectiva de prioridades, y consisten también en mecanismos importantes para la mejora del proceso de gestión.

Palabras-clave: administración estadual, evaluación de políticas públicas, administración por objetivos, indicador de desempeño, gestión presupuestaria y financiera

\section{Analysis of health structuring programs through finalistic indicators in the state of Minas Gerais}

This article aims to analyze the relationship between public expenses on health Structuring Programs, of the Minas Gerais Government, with Finalistics Indicators from that area. This study is justified by the possibility to flag how successful has been the intervention, at the strategic level, by the State Government under the Health, since the implementation of the model of "Result-based Management" in State. The results suggest a strong correlation between the variables, despite three correlations considered as not significant by statistical calculations, and one, which signaled a behavior contrary to the expectations. The regression analysis confirmed a linear relationship between the variables, for the cases that have behaved according to the hypothesis of this work. From interviews with two State Managers, one learns that although the indicators do not influence directly on the resources allocation, they guide the process of policies implementation, under a perspective on prioritization, and consist in important mechanisms for improving the management process.

Keywords: state administration, evaluation of public policies, management by objectives, performance indicator, budgetary and financial management 


\section{Introdução}

O Governo do Estado de Minas Gerais, a partir de 2003, instituiu uma cadeia de iniciativas voltadas para o aprimoramento da gestão e para a elevação da efetividade das ações governamentais. Empreendeu-se uma estratégia de desenvolvimento ancorada no ajuste fiscal, na gestão voltada para resultados e no aprimoramento da relação entre a sociedade civil e o poder público. Atrelado a essas diretrizes, enfatizou-se o planejamento, como instrumento viabilizador da construção de uma agenda de desenvolvimento de médio e longo prazo.

Ao buscar melhorar a aplicação de recursos e a obtenção dos resultados visados, o governo mineiro instituiu o monitoramento intensivo dos programas estruturadores - aqueles considerados como prioritários para o alcance dos objetivos estratégicos contemplados no planejamento.

Na área da saúde, o gasto progressivo e a necessidade de ampliação dos serviços, assim como da melhoria na qualidade desses, fazem da aplicação eficiente de recursos e das políticas públicas eficazes eixos de ação fundamentais à boa gestão pública. Nesse contexto, a Gestão para Resultados, assim como o monitoramento e avaliação das políticas de saúde, ganha distinção. Se há programas considerados estratégicos na área da saúde e elencados como iniciativas propulsoras de desenvolvimento pelo Estado, a relação entre esses e os resultados visados deve ser acompanhada e analisada. Dado que o montante de recursos alocado em tais programas é crescente, cabe analisar, assim, se tal gasto associa-se aos indicadores que mensuram o atendimento aos referidos resultados, sinalizando uma intervenção bem sucedida.

O presente trabalho objetiva, nesse sentido, fazer uma análise das correlações entre os programas estruturadores da Secretaria de Estado de Saúde (SES/MG), por meio de seus recursos liquidados, e os indicadores considerados prioritários nessa área. Há, destarte, o intuito de analisar esses indicadores, no período de 2004 a 2013; em seguida, analisar o gasto público nos referidos programas, no mesmo período; para, por fim, verificar a relação entre o gasto e a apuração dos indicadores analisados.

Pressupôs-se, dessa forma, a existência de uma relação entre o montante de recursos aplicados nos programas estruturadores da SES/MG e os indicadores elencados como estratégicos, na área. Tal hipótese embasou-se na vinculação feita pela SES/MG no momento do planejamento desses programas. Assim, as associações que serão apresentadas neste trabalho remetem às vinculações constantes nos planos de programa, planos de projeto e fichas de processo das políticas enfocadas.

Para a consecução dos objetivos propostos, foi utilizada a abordagem metodológica mista, chamada metodologia híbrida, no ensejo de se aliarem as abordagens quantitativas e qualitativas em um esforço de complementaridade (FONSECA, 2008). 0 
método quantitativo embasou-se nos cálculos feitos no Programa SPSS, um software destinado à organização e ao tratamento estatístico de dados, concretizados no intento de se identificar a natureza das correlações entre os programas e os indicadores. Para as correlações constatadas significativas e que se comportaram conforme a vinculação proposta pela SES/MG, foi realizada uma análise de regressão linear, com o objetivo de melhor fundamentar a relação encontrada entre as variáveis. A regressão linear simples é uma extensão do conceito de correlação, a qual tenta explicar uma variável, que é chamada de dependente, usando outra variável chamada de independente. O método qualitativo, por seu turno, apoiou-se nas entrevistas realizadas com o Subsecretário de Planejamento, Orçamento e Qualidade do Gasto da Secretaria de Estado de Planejamento e Gestão (Seplag/MG) e com o Secretário Adjunto da SES/ MG. As entrevistas foram condicionadas pelos resultados quantitativos.

\section{A gestão pública e o esforço para a entrega de melhores resultados à população}

Aideia de uma gestão voltada para resultados enquadra-se no contexto de crescente demanda social por bens e serviços públicos de boa qualidade, acompanhada da exigência por uma menor pressão tributária (SERRA; FIGUEROA; SAZ, 2008). Tal cenário impôs desafios ao Estado, tornando imperativa a reformulação das práticas e arranjos da administração pública. O Estado que atua voltado para resultados prioriza ações destinadas ao desenvolvimento e ao bem-estar da sociedade, compreendendo o valor público dessas ações (SERRA; FIgUeroA; SAZ, 2008).

No presente artigo, o termo Gestão para Resultados é concebido como uma estratégia que norteia as ações da administração pública rumo ao desenvolvimento, no intuito de gerar o máximo valor público possível através do uso de ferramentas de gestão - de forma coletiva, coordenada e complementar-com vistas à promoção de mudanças sociais (MORENO, 2011).

A gestão pública para resultados apoia-se em diversos mecanismos gerenciais, tais como: o planejamento estratégico das ações governamentais, organizadas muitas vezes em programas; o alargamento da flexibilidade gerencial; a instituição de indicadores de impacto e de resultado; como, também, o monitoramento e a avaliação dos efeitos alcançados - práticas que, além da mensuração das metas estabelecidas, fornecem subsídios para retroalimentação de informações, visando ao contínuo aprimoramento gerencial (CORRÊA, 2007).

O monitoramento e a avaliação de políticas públicas são, nesse ensejo, peçaschave para uma boa governança e primordiais à tomada de decisão, à gestão, à prestação de contas públicas dentro da própria administração ou voltada para os cidadãos, assim como ao alcance de metas e objetivos delineados pelo governo (MORENO, 2011). 
A formulação meticulosa de uma estratégia não implica a sua implementação natural e automática. Os sistemas de monitoramento e avaliação mensuram o desempenho de exercícios governamentais, ajudando a esclarecer e compreender falhas e sucessos; contribuindo para a melhor execução das políticas; e garantindo o aperfeiçoamento sistemático da estratégia implementada (MACKAY, 2008).

O valor dos sistemas de monitoramento e avaliação reside no uso institucionalizado da informação gerada por eles: o subsídio ao processo decisório e a conformação desses sistemas como mecanismos de retroalimentação das políticas públicas é o que os torna pertinentes e significativos à Gestão para Resultados (WERNECK et al, 2010).

Os indicadores, por sua vez, são indispensáveis aos sistemas de monitoramento e avaliação governamentais (MACKAY, 2008). Eles consistem em expressões das variáveis quantitativas e qualitativas através das quais se pode medir o progresso, observar as transformações vinculadas a uma intervenção ou analisar resultados de uma intervenção voltada para o desenvolvimento (MORENO, 2011).

Os indicadores competem para a averiguação do cumprimento das metas e objetivos institucionais, assinalando uma via para a aprendizagem organizacional e para melhor geração de valor público aos cidadãos (BONNEFOY; ARMIJO, 2005). Para acompanhar a implementação dos programas e a posterior gestão desses, portanto, é fundamental a existência de indicadores que apurem o andamento da alocação dos recursos, dos produtos, resultados e impactos planejados (JANNUZZI et al, 2009). Por meio deles, é possível prestar contas à sociedade e informá-la sobre o grau de concretização dos objetivos acordados pelo poder público (MORENO, 2011).

Ademais, como instrumento metodológico, um indicador consiste, também, em uma medida dotada de significado social - utilizada para identificar, quantificar ou operacionalizar um conceito social abstrato (JANNUZZI, 2002). Os indicadores têm a potencialidade de enriquecer a interpretação de uma realidade social, contribuindo para uma melhor orientação da análise, concepção e implementação das intervenções. Um risco a ser ressalvado, nesse sentido, é o da banalização operacional dos conceitos sociais em estudo, tal como se estes se resumissem à expressão dos indicadores (JANNUZZI, 2002).

\section{A Gestão para Resultados em Minas Gerais: componentes da agenda estratégica}

Os indicadores esquadrinhados neste trabalho estão arrolados no Plano Mineiro de Desenvolvimento Integrado (PMDI), instrumento de planejamento de longo prazo do estado, previsto na Constituição Estadual, em seu artigo 231. 
Esses indicadores, denominados finalísticos, quantificam o desempenho e o esforço empregado para o alcance das metas estratégicas mais próximas da sociedade: a redução da mortalidade infantil, o aumento do PIB per capita, a redução do déficit habitacional, o aumento da escolaridade média da população adulta, entre outras (MINAS GERAIS, 2007). Os indicadores finalísticos, portanto, seriam aqueles dotados de maior visibilidade e impacto regional, assim como aqueles sob a maior influência da atuação do governo estadual (MıNAS GERAIS, 2007).

Ademais, tais indicadores associam-se à medição do resultado esperado após a entrega de bens e serviços à sociedade, ponderando sobre o cumprimento dos objetivos definidos pelo Estado (GUIMARÃES; CAMPOS, 2009).

Segundo Pfeiffer (2006), os programas visam a benefícios amplos e significativos, de modo que, no âmbito do planejamento estratégico, seus objetivos e benefícios arrolam-se, muitas vezes, aos objetivos estratégicos de uma instituição. O programa articula um conjunto coerente de ações, cogentes e satisfatórias para enfrentar uma situação problema (PFEIFFER, 2006).

Neste estudo, entendeu-se como programa o título dado ao modo de organização das políticas públicas, no Plano Plurianual de Ação Governamental (PPAG). Os programas estruturadores, nesse sentido, compõem a agenda estratégica do Governo de Minas Gerais (Minas GeraIs, 2011B). Com o intuito de materializar a visão de futuro do estado, tais programas são selecionados no momento da elaboração do PPAG e congregados conforme sua capacidade transformadora e sua sinergia potencial (MINAS GERAIS, 2007). Eles possuem relação intrínseca com os resultados finalísticos (MINAS GERAIS, 2008a).

\section{Os indicadores finalísticos e os programas estruturadores da área de saúde: suas características e vinculações}

A seguir, passa-se a analisar, de forma específica os indicadores e os programas estruturadores enfocados por este estudo - concentrados na área de saúde, no governo estadual.

Os programas - Viva Vida, Saúde em Casa, e Urgência e Emergência - estiveram vinculados aos resultados finalísticos desde a instituição da Gestão para Resultados em Minas Gerais. O primeiro programa tem como foco o atendimento a gestantes, recém-nascidos e às crianças com até um ano de idade (MINAS GERAIS, 2008a). O Programa Saúde em Casa conta com ações de promoção, prevenção e assistência à saúde da família, inclusive o acompanhamento pré-natal em gestações não consideradas de risco (caso contrário, o atendimento é feito no âmbito do Viva 
Vida). Ademais, o Urgência e Emergência visa à condução do paciente ao ponto de atenção mais adequado e a um atendimento de qualidade, nas situações de urgência, emergência, agravos agudos à saúde e agudização de agravos crônicos (MINAS GERAIS, 2012a, 2012f).

No horizonte temporal de que trata este trabalho, alguns indicadores finalísticos estiveram presente nos planos de desenvolvimento, permanentemente. Outros, entretanto, foram apresentados de forma interina ou foram elencados como finalísticos em algum momento. O presente trabalho incide sobre aqueles indicadores que constam, por maior tempo, no PMDI. Alguns deles, não obstante, tiveram sua metodologia de cálculo modificada ao longo dos anos, como é o caso da taxa de anos potenciais de vida perdidos (APVP).

Nesse ponto, cabe expor as associações entre as políticas e os indicadores enfocados, tal como feitas no momento de planejamento - e nas quais se embasaram as análises quantitativa e qualitativa deste trabalho. Segue, no Quadro 1, a tabela de vinculação:

\section{Quadro 1 - Vinculação entre as intervenções e os indicadores em estudo}

\begin{tabular}{|c|c|c|c|c|c|}
\hline Programas & \multicolumn{5}{|c|}{ Indicadores finalísticos } \\
\hline $\begin{array}{l}\text { Regionalização } \\
\text { - urgência e } \\
\text { emergência }\end{array}$ & $\begin{array}{l}\text { Taxa de } \\
\text { APVP por } \\
\text { doenças } \\
\text { cardiovas- } \\
\text { culares }\end{array}$ & $\begin{array}{l}\text { Taxa de } \\
\text { APVP por } \\
\text { doenças } \\
\text { cardiovas- } \\
\text { culares, } \\
\text { causas } \\
\text { externas e } \\
\text { neoplasias }\end{array}$ & $\begin{array}{l}\text { Taxa de } \\
\text { resolu- } \\
\text { bilidade } \\
\text { macrorre- } \\
\text { gional }\end{array}$ & $\begin{array}{l}\text { Esperança } \\
\text { de vida ao } \\
\text { nascer }\end{array}$ & $\begin{array}{l}\text { Taxa de } \\
\text { mortalida- } \\
\text { de infantil }\end{array}$ \\
\hline Saúde em Casa & $\begin{array}{l}\text { Proporção } \\
\text { de nascidos } \\
\text { vivos de } \\
\text { mães com } \\
7 \text { ou mais } \\
\text { consultas } \\
\text { pré-natais }\end{array}$ & $\begin{array}{l}\text { Taxa de } \\
\text { resolu- } \\
\text { bilidade } \\
\text { macrorre- } \\
\text { gional }\end{array}$ & $\begin{array}{l}\text { Taxa de } \\
\text { mortalida- } \\
\text { de infantil }\end{array}$ & - & - \\
\hline Viva Vida & $\begin{array}{l}\text { Taxa de } \\
\text { mortalida- } \\
\text { de infantil }\end{array}$ & $\begin{array}{l}\text { Esperança } \\
\text { de vida ao } \\
\text { nascer }\end{array}$ & $\begin{array}{l}\text { Proporção } \\
\text { de nascidos } \\
\text { vivos de } \\
\text { mães com } \\
7 \text { ou mais } \\
\text { consultas } \\
\text { pré-natais }\end{array}$ & - & - \\
\hline
\end{tabular}

Fonte: Elaboração própria. 
Taxa de mortalidade infantil: o indicador associado às três intervenções em estudo

A taxa de mortalidade infantil (TMI) refere-se à frequência do número de óbitos de crianças com idade inferior a um ano, em relação ao número de nascidos vivos em determinado ano civil (INSTITUTo BRASILEIRo DE GEOgRAFIA E ESTATísticA, 2012). $O$ valor é calculado para cada mil crianças nascidas vivas, tem periodicidade anual e apresenta dados disponíveis pelos municípios brasileiros. Neste trabalho, a apuração da TMI tem como fonte os dados da SES/MG. O indicador pode, também, ser analisado enfocando-se os óbitos neonatais (bebês com até 27 dias) e pósneonatais (bebês entre 28 dias e 12 meses).

A taxa de mortalidade infantil integra o rol de indicadores elencados no Plano Mineiro de Desenvolvimento Integrado 2011-2030. A despeito de suas potencialidades, o indicador apresenta, naturalmente, limitações. Esse está sujeito a distorções causadas pelo sub-registro, tanto de nascidos vivos, quanto de óbitos infantis (MINAS GERAIS, 2014). Ademais, quanto menor a abrangência geográfica, maior é a possibilidade de distorção da apuração: para locais onde a frequência de nascimentos e de óbitos é reduzida, mudanças marginais causam grande variação no resultado apurado.

Segue a série histórica desse indicador, representada pelo Gráfico 1, que ilustra o comportamento da apuração, ao longo dos anos.

\section{Gráfico 1 - Tendência do indicador taxa de mortalidade infantil, Minas Gerais,} $2004-2013$

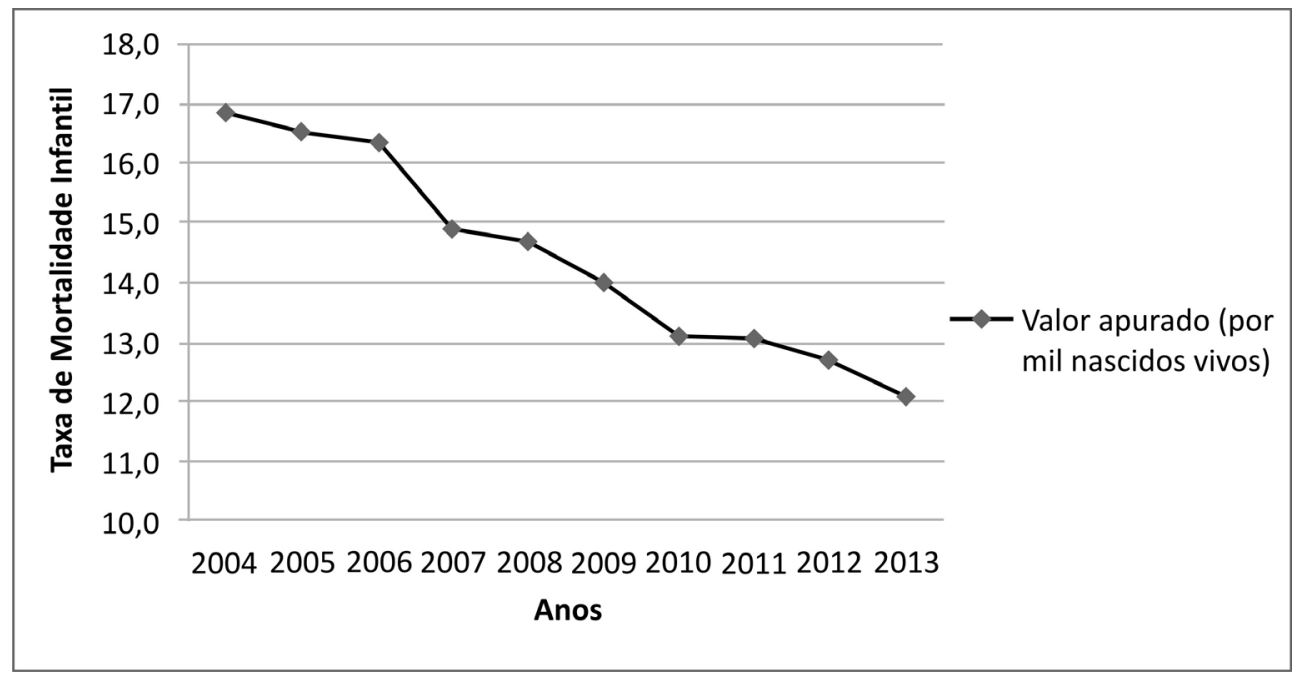

Fonte: Elaboração própria, a partir dos dados de Minas Gerais (2014). 
O gráfico de tendência explicita o comportamento decrescente do indicador. Conforme os dados apresentados, entre 2004 e 2013, a redução na taxa de mortalidade infantil no estado foi de cerca $28,4 \%$. Intui-se, portanto, que, entre esses anos, estiveram vigentes fatores que contribuíram para a redução do valor apurado. Resta saber, no entanto, se as políticas elencadas no presente trabalho têm potencial para ter composto tal rol de causalidades.

Segundo Minas Gerais (2011b), o progresso do indicador pode ser atribuído à melhoria das condições de saneamento e de saúde da população mineira. Quando analisados os óbitos infantis, de forma desmembrada, constata-se que as mortes ocorridas após o primeiro mês de vida tendem a um maior ritmo de declínio: a redução em tais óbitos indica a atenuação das causas exógenas de mortalidade, relacionadas a saneamento básico, condições de habitação, infraestrutura (BRASIL, 2009; MıNAS GERAIS, 2012c). Essa tendência também pode ser verificada no âmbito nacional (BRASIL, 2009).

Conforme os planos de projeto, processo e programa das três intervenções enfocadas por este estudo, em seu momento de concepção, essas políticas foram associadas ao resultado estratégico de redução da mortalidade infantil no estado. Assim, compreende-se que foi feita a proposição, durante o planejamento, de que à execução dessas políticas competiria a melhoria dos valores apurados pelo indicador TMI.

\section{Proporção de nascidos vivos de mães com sete ou mais consultas de pré-natal}

A Fundação Oswaldo Cruz aponta a realização de sete ou mais consultas de pré-natal como prática balizadora da atenção preventiva à gestante (FUNDAÇÃo Oswaldo CRUZ, 2012). O número "sete" refere-se à categorização do número de consultas estabelecida pelo Sistema de Informações sobre Nascidos Vivos (Sinasc).

O indicador é utilizado para mensurar o alcance das políticas de atendimento à gestante, evidenciando as condições de acesso e de cobertura da assistência pré-natal e atuando como norteador ao planejamento e ao aperfeiçoamento das políticas de saúde para o público materno-infantil.

A apuração é obtida a partir da relação entre o número de nascidos vivos de mães com sete ou mais consultas de pré-natal e o total de nascidos vivos de mães residentes em determinado espaço geográfico, no ano de referência. A periodicidade da do indicador é anual e esse pode ser aferido até o nível de município, conforme os dados do Instituto Brasileiro de Geografia e Estatística (IBGE).

Em termos de limitações, o indicador está sujeito a distorções causadas pelo sub-registro de nascidos vivos. Ademais, o cálculo não inclui gestantes que tiveram 
aborto ou um filho nascido morto. Segue o Gráfico 2, esboçado a partir da apuração mineira, no período de 2004 a 2013.

Gráfico 2 - Tendência do indicador proporção de nascidos vivos de mães com sete ou mais consultas de pré-natal, Minas Gerais, 2004-2013

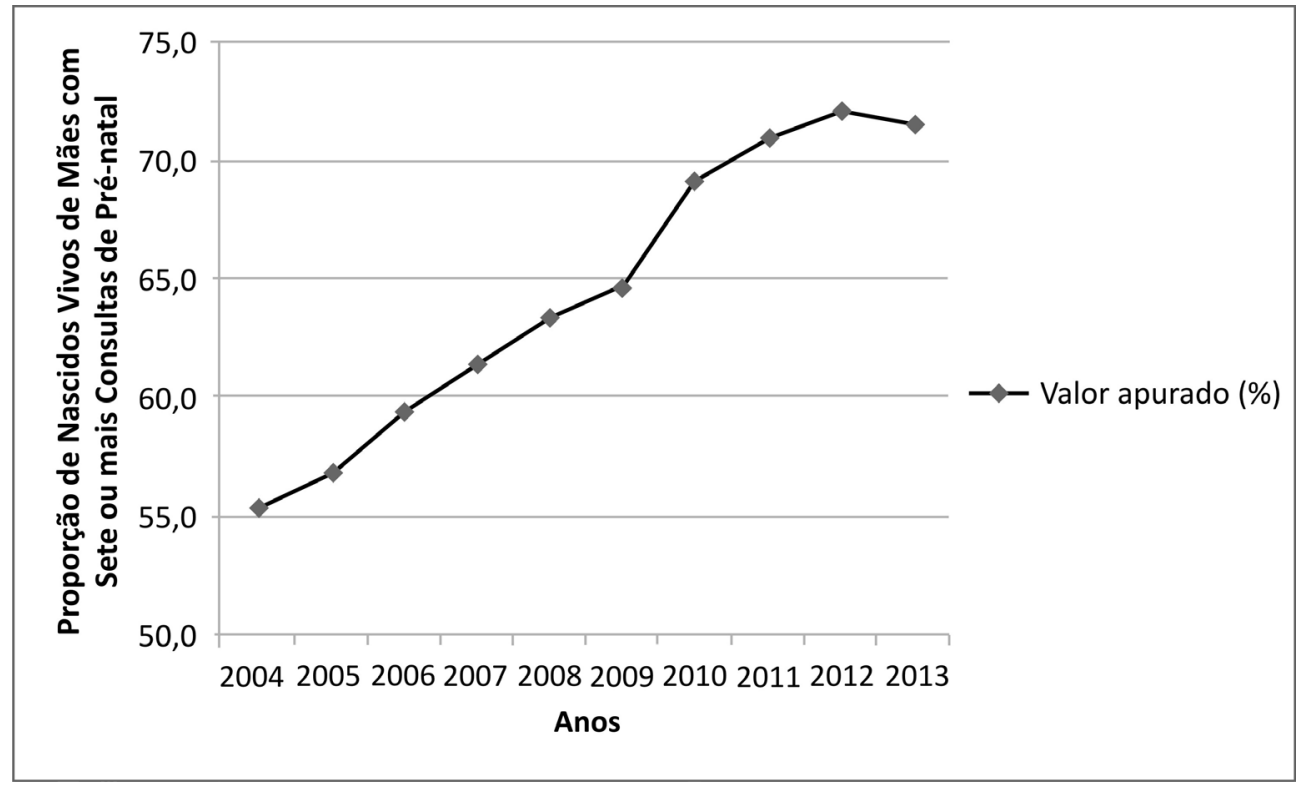

Fonte: Elaboração própria, a partir dos dados de Minas Gerais (2014).

Conforme os dados apresentados no Gráfico 2, em Minas Gerais, a tendência do indicador mostra-se favorável ao crescimento do número de gestantes que realizam o número recomendável de procedimentos de pré-natal. O indicador associa-se aos Programas Viva Vida e Saúde em Casa e teve, no período analisado, um aumento de $29 \%$ em sua apuração.

\section{Esperança de vida ao nascer}

O indicador esperança de vida ao nascer consiste na média dos anos de vida arrogados a um recém-nascido - dado o padrão corrente de mortalidade na população, em determinado espaço geográfico e em determinado momento do tempo (BRASIL, 2010).

Ao apontar o número médio de anos de vida que se espera de uma criança recém-nascida, o indicador leva em conta, para fins de sua apuração, tanto a mortalidade infantil, quanto os riscos de morte associados a crianças, jovens, adultos e idosos (PNUD, s.d.). Considera-se, assim, a mortalidade ao longo do ciclo 
de vida, assinalando uma medida sintética da longevidade dos cidadãos (MINAS GERAIS, 2014).

A fórmula do indicador corresponde ao tempo cumulativo vivido por determinada geração, em relação ao número de nascimentos dessa mesma geração. O valor, em anos, é aferido com periodicidade anual e tem como unidade geográfica os estados. $O$ dado do indicador tem como fonte o IBGE.

Tal como exposto pelo Gráfico 3, a tendência do indicador no estado de Minas Gerais tem se mostrado favorável a uma maior longevidade da população mineira.

Gráfico 3 - Tendência do indicador esperança de vida ao nascer, Minas Gerais, 2004-2012

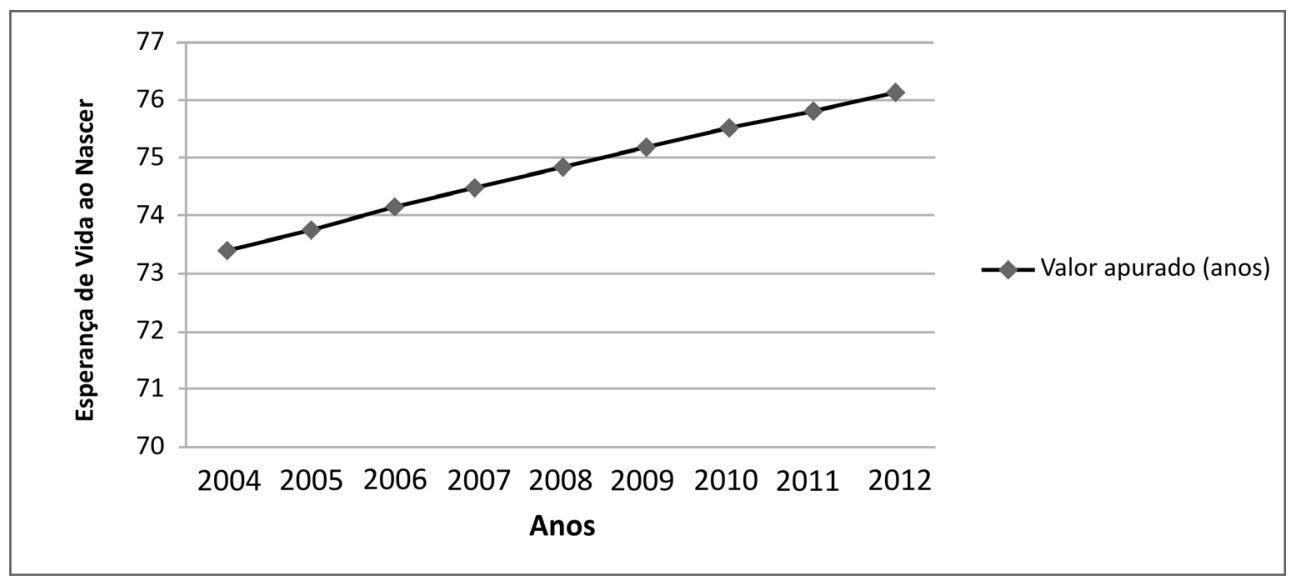

Fonte: Elaboração própria, a partir dos dados de Minas Gerais (2014).

A apuração do indicador aumentou em cerca de 3,7\% entre 2004 e 2012. Esse comportamento positivo deve-se, entre outros fatores, à redução da taxa de mortalidade infantil no estado (MINAS GERAIS, 2014).

Entre os programas enfocados neste trabalho, vinculam-se a esse indicador a política Viva Vida e a política de Urgência e Emergência.

\section{A taxa de anos potenciais de vida perdidos}

O quantitativo das mortes de uma população é usualmente descrito pelas taxas de mortalidade (bruta e específicas). Embora pertinente, a ponderação apenas quantitativa de mortes, sopesadas pelas causas no caso das taxas específicas, não compreende integralmente o fenômeno da mortalidade (LUCENA; SOUSA, 2009).

O indicador taxa de anos potenciais de vida perdidos é apresentado como alternativa aos critérios convencionais de mensuração da mortalidade. Tal indicador 
destina-se a medir a mortalidade prematura, associando-a à magnitude dos óbitos e ao valor social desses (LUCENA; SOUSA, 2009).

Como indicador finalístico, o APVP, até o ano de 2010, era mensurado considerandose os anos potenciais de vida perdidos por doenças cardiovasculares e diabetes. 0 PMDI 2011, contudo, instituiu o indicador como parâmetro a ser calculado a partir das causas externas, doenças cardiovasculares e neoplasias. A mudança se deu no ensejo de se contemplar as principais causas de mortalidade no Estado.

Para ambos indicadores, o cálculo se dá a partir do agrupamento dos óbitos, com base nas referidas causas, e na idade do falecimento. Na fórmula do indicador, é realizado o somatório das diferenças entre a esperança de vida dos indivíduos de uma população e a idade de falecimento desses. Divide-se, então, essa soma pela população residente, no ano considerado. $O$ indicador é apurado anualmente até o nível de município, a partir dos dados do Datasus e do IBGE. Tal como a mortalidade infantil, a polaridade desse indicador é classificada como "menor, melhor", de modo que uma redução no valor aferido implica em uma melhora do indicador e, consequentemente, do fenômeno enfocado.

$\mathrm{O}$ indicador apresenta limitações no que tange à possibilidade de distorções, em razão do sub-registro dos óbitos e da imprecisão ocasional de suas causas. Ainda, adota-se a expectativa de vida total para o cálculo do APVP, negligenciando-se as discrepâncias entre a longevidade feminina e a masculina.

O indicador, atualmente denominado finalístico pelo governo mineiro, apresentou, entre 2004 e 2012, a melhora de sua apuração em cerca de $10 \%$. No Gráfico 4, apresenta-se tendência do indicador entre os referidos anos.

\section{Gráfico 4 - Tendência do indicador APVP por doenças cardiovasculares, causas externas e neoplasias, Minas Gerais, 2004-2012}

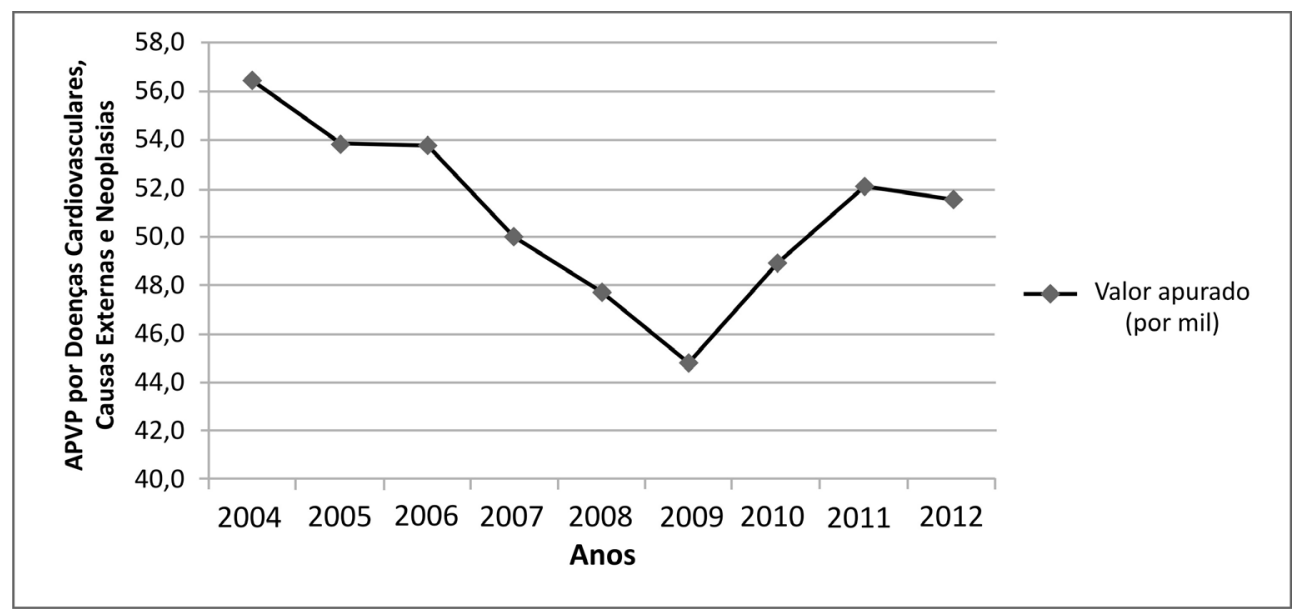

Fonte: Elaboração própria, a partir dos dados de Minas Gerais (2014). 
Como observado no Gráfico 4, o indicador apresentava a tendência de redução até o ano de 2009, quando o valor apurado, até 2011, apresentou o salto de sete anos. Tal fato pode ser explicado pelo comportamento das causas de mortalidade quando analisadas separadamente: entre 2009 e 2011, o número de anos perdidos para cada uma das causas apresentou um aumento. Em 2012, entretanto, a apuração voltou a cair com a variação de 0,5 anos potenciais de vida perdidos. 0 programa estruturador que se vincula ao alcance das metas do APVP é o Urgência e Emergência.

\section{A taxa de resolubilidade macrorregional}

A resolubilidade refere-se ao grau de acolhimento aos cidadãos em sua demanda pelos serviços públicos de saúde. Essa é uma "medida percentual da capacidade de atendimento ambulatorial e/ou hospitalar da população residente em sua própria região, micro ou macro" (MALACHIAS et al., 2010). Nas macrorregiões de saúde mineiras, avalia-se, por meio do indicador de resolubilidade macrorregional, o alcance da prestação dos serviços terciários de saúde, verificando-se a existência de vazios assistenciais (MALACHIAS et al., 2010).

A atenção de nível terciário compreende os procedimentos de alta complexidade ( $\mathrm{AC}$ ) e média complexidade hospitalar especial (MCHE): ofertados nas macrorregiões de saúde, esses são serviços de alto custo e propriedade tecnológica e que, portanto, requerem escala. $O$ indicador finalístico, destarte, mune o governo estadual de informações que podem contribuir para a oferta de serviços pertinentes, em locais apropriados e em volumes adequados à população (MALACHIAS et al., 2010).

O indicador é calculado pela relação entre o número de internações do nível terciário que ocorrem nos hospitais da macrorregião em que o paciente reside, e o número de internações do nível terciário em Minas Gerais, para pacientes residentes no estado. A apuração é realizada mensalmente e apresenta dados disponíveis por município, tendo como fonte a SES/MG.

Em Minas Gerais, constata-se o aumento de 2,3\% no valor apurado pelo indicador entre os anos de 2004 a 2013. Contudo, segundo Lélis (2012), a série histórica do indicador, para anos anteriores a 2008, apresenta diferenças em razão da natureza das informações que compõem o banco de dados.

Além disso, apesar de que, desde 2004, as apurações mantenham-se acima dos $87 \%$, como denota o Gráfico 5, ainda há deficiências nos territórios mineiros, no que tange à assistência integral aos cidadãos, nos serviços de saúde especializados. 
Gráfico 5 - Tendência do indicador taxa de resolubilidade macrorregional, Minas Gerais, 2004-2013

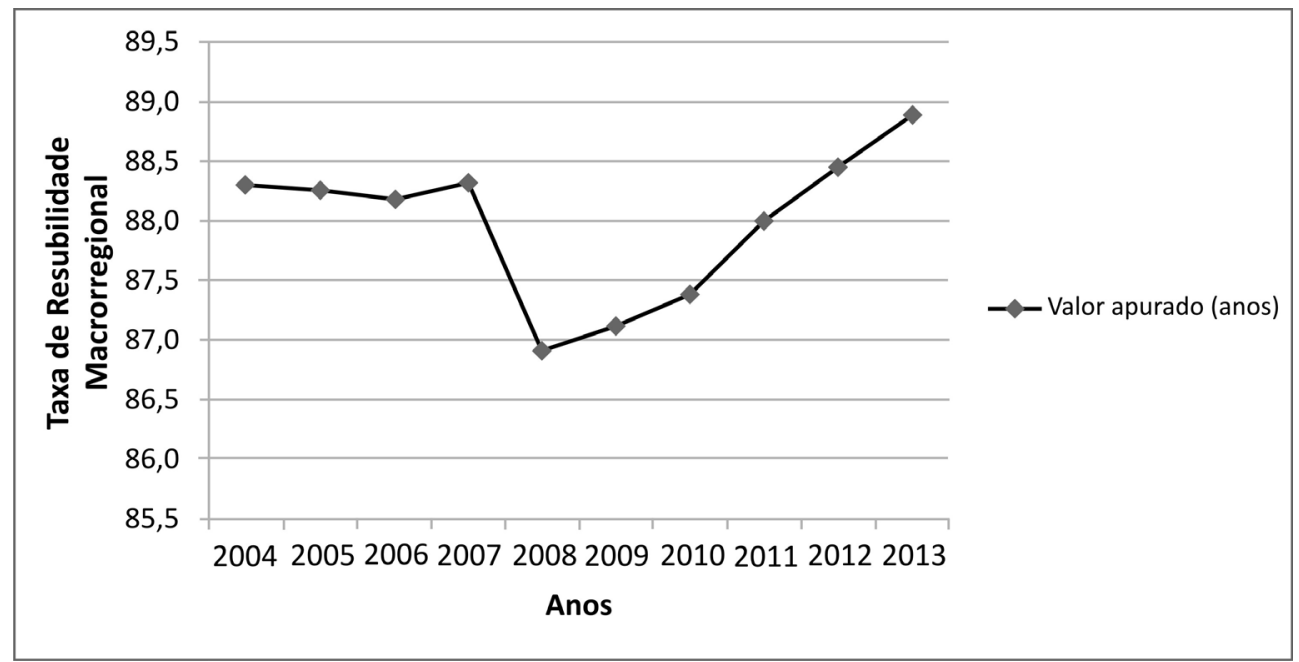

Fonte: Elaboração própria, a partir dos dados de Minas Gerais (2014).

O indicador apresenta, também, limitações: além de restrito às informações das unidades vinculadas ao SUS, o indicador pode ser distorcido em razão da superestimação do número de internações hospitalares de alta complexidade, as quais são delineadas através do critério de pagamento por procedimento, seguido pelo SUS. Ainda, são desconsiderados, para a apuração, os atendimentos de atenção hospitalar terciária ocorridos fora do território mineiro - os quais seriam relevantes, no âmbito das macrorregiões fronteiriças.

O indicador taxa de resolubilidade macrorregional vincula-se aos Programas Estruturadores Saúde em Casa e Urgência e Emergência, conforme os documentos de planejamento dessas intervenções. Dessa forma, a estruturação da Rede de Urgência e Emergência nas macrorregiões de saúde mineiras, assim como a estruturação da rede de atenção primária no estado, associam-se ao resultado finalístico de melhoria da atenção terciária em saúde, no âmbito macrorregional.

O valor gasto nos programas estruturadores e o comportamento dos indicadores finalísticos: a relação entre a despesa liquidada e a série histórica dos indicadores

Caracterizados os indicadores e programas em estudo, cabe apresentar a representatividade desses sob o ponto de vista orçamentário. Para tal, os valores liquidados nas intervenções foram deflacionados pelo Índice Nacional de Preços ao Consumidor Amplo (IPCA), a preços de dezembro de 2013. Analisando o Fundo Estadual de Saúde (FES), principal unidade orçamentária da SES/MG, vislumbra- 
se que o valor executado nas intervenções analisadas cresceu, significativamente: passando de $\mathrm{R} \$ 3.343 .020,30$, em 2004, ano de implantação dos Programas, para R\$ 395.054.276,62 liquidados, em 2013.

Assim, ao longo do período analisado, apesar de algumas oscilações, ocorreu um aumento no comprometimento de recursos para as três políticas. Apenas no Programa Saúde em Casa, foram liquidados $\mathrm{R} \$$ 1.160.706.207,25 no período.

O valor total liquidado na política de Urgência e Emergência, por sua vez, representou o maior montante, em comparação às outras intervenções: foram liquidados R\$ 4.647.480.794,49, no período de referência.

O Programa Viva Vida apresentou o maior aumento no valor liquidado, para o período. A variação média no montante de recursos liquidados para esse programa, entre $2003-2013$, foi de $45.142 \%$ - contra 1.499,49\% e 1.336\% do Saúde em Casa e do Urgência e Emergência, respectivamente.

Destarte, denota-se que, nesses nove anos, tanto o valor liquidado nas três intervenções, quanto a apuração dos indicadores analisados, apresentaram um comportamento progressivo. Resta, portanto, analisar a correlação entre o gasto público nos programas enfocados e o comportamento dos indicadores finalísticos a que esses se associam.

\section{Análise quantitativa}

O método estatístico é utilizado para oferecer uma descrição quantitativa de um fenômeno (MARCONI; LAKATOS, 2001). A análise quantitativa, utilizada para fornecer informações objetivas acerca da magnitude, do comportamento e da relação entre variáveis, tem como uma de suas características a capacidade inferencial (MORESI, 2003). No caso deste trabalho, ressalta-se que as amostras apresentam um número reduzido de componentes, de modo que a confiabilidade das inferências constata-se comprometida. A despeito da necessidade de que futuros estudos sejam feitos para aprimorar a capacidade de generalização dos resultados, reitera-se a importância desta análise, no intento de se apontarem indícios sobre a efetividade do gasto público.

Nesse sentido, foram calculadas as correlações. Consideram-se válidas as correlações que apresentam significância inferior a 0,05. Caso contrário, considerase que o resultado não possui suporte razoável para aceitação (DANCEY; REIDY, 2006).

Os cálculos apontaram como não significativos os resultados para o Programa Saúde em Casa e o indicador taxa de resolubilidade macrorregional (significância = 0,99); bem como para o gasto no Programa Urgência e Emergência e a apuração dos indicadores esperança de vida ao nascer (significância $=0,32$ ) e taxa de mortalidade infantil (significância $=0,48$ ). Um caso peculiar ocorreu quando correlacionado 
o gasto no Programa Urgência e Emergência e os dados do indicador taxa de resolubilidade macrorregional.

O coeficiente de correlação, que aponta a magnitude com que as variáveis se relacionam e a direção desse relacionamento, pode variar de -1 a 0 e de 0 a 1 (DANCEY; REIDY, 2006). O valor de 0 representa a inexistência de relação entre as variáveis. Os extremos -1 e 1 sintetizam uma relação perfeita, porém, com direcionamentos opostos.

O indicador taxa de resolubilidade macrorregional possui polaridade positiva: uma apuração elevada denota a melhoria do fenômeno social mensurado. Assim, era esperado que o relacionamento entre a série histórica e o gasto no Programa Urgência e Emergência fosse positivo. A correlação encontrada (significância = 0,001 ; coeficiente de correlação $=-87,90$ ) corresponde a uma correlação significativa e forte, porém negativa. O que está sendo indicado, assim, é que um aporte de recursos na política de Urgência e Emergência poderia ocasionar uma redução na resolubilidade das macrorregiões de saúde estaduais. Esse resultado contradiz a hipótese deste trabalho, embasada na vinculação feita pela SES/MG no momento do planejamento da intervenção.

Para as demais correlações, as quais se comportaram conforme o planejamento da SES/MG, foi realizada uma análise de regressão linear, no ensejo de se aprofundar a apreciação estatística dos resultados encontrados. A regressão linear intenta identificar a relação entre duas variáveis: uma denominada dependente e outra variável designada independente.

Com a apuração das correlações, foi encontrado o coeficiente de determinação, o qual se refere ao grau em que a variação de uma variável pode ser explicada pela variação da outra (DANCEY; REIDY, 2006). Logo, quanto maior o valor desse coeficiente, mais explicativo é o modelo que reflete a relação entre as variáveis. 0 cálculo desse coeficiente corresponde ao quadrado do coeficiente de correlação.

Na regressão, utilizou-se de uma equação linear simples: $Y_{i}=\alpha+\beta x_{i}+$ erro $_{i}$, em que $\alpha$ e $\beta$ são os parâmetros do modelo, representando, respectivamente, a interceptação da reta com o eixo vertical e o coeficiente angular da reta. A partir da regressão, foram encontradas medidas que complementam a análise da correlação: o valor de $R^{2}$ ajustado, o valor $f$ de significação e P-valor. O primeiro indica a força da relação linear entre a variável independente e a variável dependente. $O R^{2}$ ajustado sugere que o modelo explica um percentual da variação da variável dependente e, quanto mais próximo de $100 \%$, maior a capacidade explicativa do modelo. O valor $f$ de significação consiste no nível de significância com o qual se aceita a hipótese nula da regressão, a qual indica que o modelo não é adequado. Para um intervalo de 
confiança de $95 \%$, um valor de $f$ com significação menor que $5 \%$ rejeita a hipótese nula, considerando o modelo de relação entre as variáveis como adequado. Para o mesmo intervalo de confiança, se o P-valor for menor que $5 \%$, o coeficiente $\beta$ da reta de regressão é significativo.

O Quadro 2 apresenta os dados encontrados, de forma segmentada pelos programas em estudo.

\section{Quadro 2 - Correlações encontradas entre os programas e os indicadores estudados}

\begin{tabular}{|c|c|c|c|c|c|c|}
\hline \multicolumn{7}{|c|}{ Programa Viva Vida } \\
\hline Indicador & $\begin{array}{l}\text { Coeficiente } \\
\text { de } \\
\text { correlação }\end{array}$ & Significância & $\begin{array}{l}\text { Coeficiente } \\
\text { de deter- } \\
\text { minação } \\
\left(R^{2}\right)\end{array}$ & $\begin{array}{l}\mathrm{R}^{2} \text { ajus- } \\
\text { tado }\end{array}$ & $\begin{array}{l}\text { Valor } \\
f \text { de } \\
\text { signifi- } \\
\text { cação }\end{array}$ & Valor $p$ \\
\hline $\begin{array}{l}\text { Taxa de } \\
\text { mortalida- } \\
\text { de infantil }\end{array}$ & $-90,70 \%$ & 0,000 & $82,26 \%$ & $80,11 \%$ & $0,03 \%$ & $0,03 \%$ \\
\hline $\begin{array}{l}\text { Esperança } \\
\text { de vida ao } \\
\text { nascer }\end{array}$ & $90,50 \%$ & 0,001 & $81,90 \%$ & $79,22 \%$ & $0,08 \%$ & $0,08 \%$ \\
\hline $\begin{array}{l}\text { Proporção } \\
\text { de nasci- } \\
\text { dos vivos } \\
\text { de mães } \\
\text { com sete } \\
\text { ou mais } \\
\text { consultas } \\
\text { pré-natais }\end{array}$ & $90,60 \%$ & 0,000 & $82,08 \%$ & $80,03 \%$ & $0,03 \%$ & $0,03 \%$ \\
\hline \multicolumn{7}{|c|}{ Programa Saúde em Casa } \\
\hline Indicador & $\begin{array}{l}\text { Coeficiente } \\
\text { de } \\
\text { correlação }\end{array}$ & Significância & $\begin{array}{l}\text { Coeficiente } \\
\text { de deter- } \\
\text { minação } \\
\left(\mathrm{R}^{2}\right)\end{array}$ & $\begin{array}{l}R^{2} \text { ajus- } \\
\text { tado }\end{array}$ & $\begin{array}{l}\text { Valor } \\
f \text { de } \\
\text { signifi- } \\
\text { cação }\end{array}$ & Valor $p$ \\
\hline $\begin{array}{l}\text { Taxa de } \\
\text { mortalida- } \\
\text { de infantil }\end{array}$ & $72,40 \%$ & 0,018 & $52,42 \%$ & $46,46 \%$ & $1,79 \%$ & $0,00 \%$ \\
\hline $\begin{array}{l}\text { Proporção } \\
\text { de nasci- } \\
\text { dos vivos } \\
\text { de mães } \\
\text { com sete } \\
\text { ou mais } \\
\text { consultas } \\
\text { pré-natais }\end{array}$ & $65,50 \%$ & 0,040 & $42,90 \%$ & $35,81 \%$ & $3,97 \%$ & $3,97 \%$ \\
\hline
\end{tabular}




\begin{tabular}{|l|l|l|l|l|l|l|}
\hline \multicolumn{2}{|c|}{ Programa Urgência e Emergência } & $\begin{array}{l}\text { Coeficiente } \\
\text { de deter- } \\
\text { minação } \\
\left(\mathrm{R}^{2}\right)\end{array}$ & $\begin{array}{l}\mathrm{R}^{2} \text { ajus- } \\
\text { tado } \\
\text { de } \\
\text { correlaçãonte }\end{array}$ & $\begin{array}{l}\text { Valor } \\
f \text { de } \\
\text { signifi- } \\
\text { cação }\end{array}$ & Valor $p$ \\
\hline $\begin{array}{l}\text { APVP por } \\
\text { doenças } \\
\text { cardiovas- } \\
\text { culares e } \\
\text { diabetes }\end{array}$ & $-84,00 \%$ & 0,036 & $70,56 \%$ & $63,20 \%$ & $3,64 \%$ & $3,64 \%$ \\
\hline $\begin{array}{l}\text { APVP por } \\
\text { doenças } \\
\text { cardiovas- } \\
\text { culares, } \\
\text { causas } \\
\text { externas e } \\
\text { neoplasias }\end{array}$ & $-81,00 \%$ & 0,008 & $65,61 \%$ & $60,19 \%$ & $0,85 \%$ & $0,85 \%$ \\
\hline
\end{tabular}

Fonte: Elaboração própria.

Como ressaltado, os resultados acima indicam a presença de correlação entre os indicadores finalísticos e os programas estruturadores. Os coeficientes mais fortes foram aqueles referentes ao Programa Viva Vida. Constatou-se que essa política, como esperado, está fortemente relacionada à redução da mortalidade infantil, ao aumento da longevidade da população mineira e ao crescimento do número de nascidos vivos cujas mães realizaram o número recomendado de pré-natais. Como os valores dos coeficientes de correlação são elevados, o mesmo ocorre para o coeficiente de determinação. Como o $R^{2}$ ajustado do modelo de regressão linear também foi alto, pode-se inferir que o aumento do valor alocado na manutenção e ampliação da Rede Viva Vida pode, segundo o modelo, estar associado à melhoria das condições de saúde sintetizadas pelos indicadores em questão.

O mesmo não ocorreu no Programa Saúde em Casa, em que as correlações com os indicadores TMI e proporção de nascidos vivos de mães com sete ou mais consultas de pré-natal foram respectivamente $52,42 \%$ e $42,90 \%$. No mesmo sentido, o modelo de regressão linear apresentou $R^{2}$ ajustados inferiores a $50 \%$. Pode-se inferir que há uma gama de outros fatores que poderiam explicar mais da metade da variação das séries históricas desses indicadores; fatores, portanto, passíveis de influírem sobre a melhoria dos resultados finalísticos em questão. Entretanto, é possível inferir que, segundo o modelo, um incremento no gasto do Programa Saúde em Casa tem um impacto positivo, porém pequeno, na redução do risco de morte para os nascidos vivos, até um ano de idade, e no aumento do número desses, para os quais a gestação foi devidamente acompanhada. 
O Programa Urgência e Emergência apresentou correlações fortes e positivas tanto com o Indicador APVP por doenças cardiovasculares e diabetes, quanto com o APVP por doenças cardiovasculares, causas externas e neoplasias. Os indicadores APVP possuem polaridade negativa, de modo que é a redução deles que se associa ao crescimento do montante de recursos alocados na Rede de Urgência e Emergência do estado, caracterizando um relacionamento negativo entre as variáveis.

É possível, portanto, que o aumento dos recursos alocados nessa política, nos últimos nove anos, tenha sido responsável pela redução das mortes prematuras no estado. O poder de explicação da variação desses indicadores pela variação do valor gasto na Rede de Urgência é superior a 60\%, como indicado pelos cálculos de correlação e confirmado pelos dados obtidos a partir da regressão linear.

As peculiaridades apresentadas pela análise estatística carecem de uma abordagem qualitativa, para que o fenômeno de associação entre as variáveis seja melhor compreendido.

\section{Análise qualitativa}

Diante da análise estatística, indagou-se primeiramente aos entrevistados sobre a observância à apuração dos indicadores, no processo de alocação de recursos. De posse dos coeficientes de correlação e determinação, entendeu-se que seria importante verificar se a alocação de recursos ocorre de forma condicionada ao atendimento dos resultados finalísticos. Constatou-se, porém, que os resultados dos indicadores, no tocante à alocação de recursos, inserem-se em um contexto mais amplo: eles estão contidos na lógica dos processos de gestão. Destarte, esses indicadores não implicam diretamente a alocação de recursos, como assinala o Subsecretário de Orçamento:

[...] a inserção dos resultados dos indicadores na alocação de recursos não tem um processo formal de instrução no processo de alocação de recursos. $\mathrm{Na}$ verdade, a partir do monitoramento intensivo, todos os gestores envolvidos, tanto da Secretaria de Saúde, quanto da Secretaria de Planejamento, acompanham esses indicadores que são pactuados anualmente. De forma que esses indicadores estão na cabeça de todo mundo. Mesmo porque esses indicadores não deveriam condicionar a alocação de recursos: se os indicadores vão mal, a gente coloca mais recursos, sucessivamente? Ou, se vão bem, eu coloco mais? Como que eles pautariam essa alocação de recursos? Não tem um processo formal de, se vai bem, coloca mais; ou se vai mal, coloca mais; ou coisa nesse sentido. 
O fato de você monitorar e acompanhar anualmente os resultados é como se você acompanhasse o desempenho da organização; e a alocação de recursos vai conforme esse desempenho. [...] Como os resultados desses indicadores afetam a alocação dos recursos... Diretamente, não afetam. Porque são indicadores de políticas, que têm uma estruturação que irá gastar alguns anos. Eles entram num contexto de debate da pactuação dos resultados, mas não numa relação direta: se bateu meta, o indicador recebe ou não recebe dinheiro. A discussão é mais ampla. (Subsecretário de Planejamento, Orçamento e Qualidade do Gasto da Seplag/MG).

Assim, o Subsecretário aponta que existem outros fatores que influem diretamente sobre o processo de alocação dos recursos, a nível estratégico, no governo estadual. O modo como as políticas de saúde foram estruturadas seria um deles, tal como foi assinalado no trecho da entrevista transcrito a seguir:

Mas no caso da saúde, eu acho diferente dos demais. Ela e a Secretaria de Educação, como têm um processo formal de estruturação das políticas públicas, conforme as suas atribuições; e, no caso desses programas, eles refletem a implantação de algumas redes, que é a forma como estruturalmente a Saúde organizou sua política... A aferição dos resultados não está diretamente ligada a essa alocação de recursos, dado que a implantação da rede demanda algum tempo de maturação e eu vou ter que colocar dinheiro durante um período para que, daqui uma década, essa rede implantada possa ter seus resultados aferidos com mais equidade. Como você tem um processo de implantação de uma rede, num estado inteiro, esse processo de alocação de recursos não está determinado pelo resultado alcançado pelo indicador, afinal. E, sim, pelos processos de gestão e acompanhamento, na verdade, há mais conexão entre o monitoramento e o processo de gestão desses programas. (Subsecretário de Planejamento, Orçamento e Qualidade do Gasto da Seplag/MG).

Sobre essa questão, o Secretário Adjunto da SES/MG complementa a argumentação, ressaltando as especificidades da alocação de recursos no âmbito da saúde. Segundo ele, o sistema de saúde ainda carece de recursos para que todos os serviços sejam oferecidos em sua qualidade ideal e alcance pleno de resultados. Logo, a relação entre os recursos alocados e a apuração dos indicadores finalísticos se dá, principalmente, em sua visão, sob o ponto de vista da priorização:

Bom, primeiro, como ponto de partida, a gente tem que considerar que há uma escassez de recursos, ainda. Se a gente fosse financiar todas as redes prioritárias, em funcionamento pleno, com $100 \%$ de cobertura, seria muito mais do que a gente tem. Bom, o orçamento é crescente. A partir do momento que o estado começou a cumprir os $12 \%$ do que se considera como gasto em 
saúde, depois da publicação da Lei Complementar 141, acho que a tendência é de a gente, gradativamente, atingir esse patamar. Por não ter, hoje, essa rede completamente financiada, até, em alguns lugares, eu não tenho alguns pontos de atenção que eu criei para as redes, a alocação acaba não sendo um processo muito lógico. Ela vai variar de programa pra programa e de rede pra rede.

Como eu vejo a questão dos indicadores para orientação da alocação dos recursos: eu vejo que ela faz sentido, no momento em que eu tenho que priorizar uma região em detrimento de outra. Como no caso da Rede de Urgência e Emergência: como eu não tenho condições de chegar e implantar nas 13 regiões de uma vez, indicador é um bom orientador pra isso. Lembrando de Pareto, eu vou pegar a região que tem maior índice, atacar lá primeiro e ter maior impacto no conjunto de resultados do estado. É o mesmo critério que eu uso para definir quais as redes que eu priorizo. Saúde é universal e integral, desde a Constituição. Saúde tem que atender tudo, pra todos. Partindo do fato que eu tenho escassez de recursos e etc., eu tenho que eleger prioridades. Eleger prioridades, a partir de critérios, é olhar indicador (Secretário Adjunto de Saúde da SES/MG).

Neste ponto, é importante salientar que as perspectivas dos dois entrevistados apresentam vieses distintos, porém complementares. Ademais, sobre a vinculação entre as referidas variáveis, destaca-se, ainda, uma das falas do Secretário Adjunto de Saúde, que vai ao encontro do argumento apresentado pelo Subsecretário da Seplag:

Quando eu defini minhas redes prioritárias, eu olhei indicador. E isso faz todo sentido. Agora, uma vez que você implantou as redes em todo o estado, pra que serve o indicador: aí ele serve para ser parte do sistema de gestão. Pra dar foco à gestão. $O$ casamento com a alocação de recursos faz todo o sentido se o nosso olhar for esse.

Agora, se o nosso olhar for: dar mais recurso para um programa ou para outro, você tem que entender que vão ter $n$ variáveis além desses indicadores. Como o recurso repassado em função do número de equipes do Saúde em Casa; e a alocação de recursos onde a Rede de Urgência já está implantada. Não são esses indicadores (finalísticos) que geram a alocação de recursos, $a$ priori (Secretário Adjunto de Saúde da SES/MG).

Assim, em relação aos fatores que orientam diretamente a alocação dos recursos nas políticas estratégicas mineiras, conforme os entrevistados, não são os indicadores finalísticos os parâmetros que sobressaem. Destacam-se como norteadores do processo de alocação fatores como a estrutura, em vigor, das políticas de saúde - como, por exemplo, a lógica de estruturação das redes, a nível regional. 
Entretanto, o Secretário Adjunto da SES/MG ressaltou a importância da utilização desses indicadores como critérios para a alocação dos recursos, nessas políticas, no momento inicial de sua implementação, sob a perspectiva de priorização.

A despeito da não primazia dos indicadores como fatores determinantes à alocação de recursos, os coeficientes encontrados, exibidos no Quadro 2, são coerentes ao esperado, tendo em vista a vinculação feita nos planos de programa, planos de projeto e nas fichas de processo. Essa congruência foi atribuída pelos entrevistados ao modelo de Gestão para Resultados no estado. O Subsecretário de Orçamento, a esse respeito, declarou:

A gente espera que as pessoas que estão executando as políticas públicas estejam tendo sucesso na implementação dos projetos. É interessante você ver esses resultados de forma desagregada, porque de forma agregada você não acha correlação. Olhando no atacado, você perde muita coisa, muita variável. Olhando no varejo, é mais correto mesmo. Mas que bom! É isso o que a gente estava imaginando mesmo. Se eu passo a repetir o modelo 20 anos, a princípio não fazendo sentido a meta que eu pactuo de um ano com o resultado apurado... Mas se eu passo a repetir e imprimir um ritmo maior na gestão dos recursos e na gestão dos programas, eu espero que isso tenha resultados mais positivos (Subsecretário de Planejamento, Orçamento e Qualidade do Gasto da Seplag/MG).

O modelo de Gestão para Resultados, instituído em Minas Gerais desde 2003, foi apontado, portanto, na perspectiva dos entrevistados, como fator decisivo para que os recursos alocados nos programas em estudo pudessem cumprir sua finalidade, em termos de materialização dos resultados de governo. Nesse mesmo sentido, o Secretário Adjunto de Saúde assinala:

Eu vou ter que remeter a uma frase do Dr. E. V. M. (antigo consultor em Saúde Pública do Banco Mundial e da Secretaria Estadual de Saúde de Minas Gerais), de quando a gente começou a trabalhar com o sistema gerencial, pelo processo do governo, na Gestão para Resultados... e vou te falar que isso tudo é realmente um grande processo. Por exemplo, desde o começo, mortalidade infantil está com a SES/MG. É um indicador que nos acompanha. Porque: no mundo inteiro, um indicador de desenvolvimento social e de êxito em saúde pública é reduzir mortalidade infantil. Só que o $\mathrm{E}$. falava uma coisa que é muito sábia. Ele falava: vocês pactuam mortalidade infantil, mas como o prestador, o município, quem realmente vai te dar esse resultado não está bem amarrado no seu sistema gerencial, vocês pactuam e rezam. E rezamos bem? Não, não é que a gente reza bem. O indicador veio caindo desde 2003, porque, em algum patamar que você está em mortalidade infantil, como 
saúde tem que levar em conta determinantes sociais, condicionantes... Ou seja, resultado em saúde não depende só do esforço da saúde: esse indicador cai. O estado está se desenvolvendo socialmente? Está. As mulheres estão se tornando mais educadas? A educação está fazendo bem o papel dela? Esse indicador vai cair.

Eu acho, enfim, que muito do que está sendo observado no resultado, das correlações que foram identificadas, não significa um êxito direto de um ou outro programa, ou da correlação que a gente está propondo entre esses programas e esses indicadores, do jeito que eles estão no PMDI, mas significa um resultado de um sistema de saúde. E saúde no sentido mais amplo: como reflexo da melhoria no sistema de educação... de um conjunto! Mas a gente vai chegando num patamar, onde teremos que ser exitosos em ações mais específicas e pontuais (Secretário Adjunto de Saúde da SES/MG).

Assim, dois pontos foram destacados pelos entrevistados como possíveis responsáveis para as fortes correlações encontradas: o sistema de Gestão para Resultados, com seus mecanismos de pactuação - acordos de resultado - e de monitoramento intensivo; e a multiplicidade causal das políticas de saúde. Sobre esse último, cabe ressalvar a última colocação do Secretário Adjunto de Saúde: para um determinado estágio de condições sociais e de saúde, exigem-se ações mais específicas e pontuais para que os indicadores em questão continuem a evoluir. Assim, o contínuo avanço dos indicadores finalísticos estudados requer o progressivo refinamento do sistema de gestão. $O$ atendimento aos resultados finalísticos e, portanto, à visão de futuro do governo mineiro atrela-se, sob esse prisma, à sofisticação das políticas e ao aprimoramento do modelo de gestão.

Quanto aos elevados coeficientes de correlação e determinação encontrados para o Programa Viva Vida, indagou-se ao Secretário acerca dos motivos que explicam essa forte associação. A esse respeito, o Secretário argumentou:

Eu acho que porque é o programa que guarda mais relação direta com os indicadores. A razão de ser do Viva Vida é reduzir a mortalidade infantil. E pra reduzir mortalidade infantil o que ele tem que atacar? 0 principal problema de processo da mortalidade infantil é: gestante não sendo acompanhada no pré-natal. Então ele tem que atacar a proporção de nascidos vivos de mães com sete ou mais consultas de pré-natal. É isso, ele é um programa muito focado. Diferente do Saúde em Casa que é um programa mais abrangente (Secretário Adjunto de Saúde da SES/MG).

Dessa forma, as correlações encontradas, no âmbito do Programa Viva Vida, podem ser justificadas pela abrangência do escopo dessa política, assinalado pela finalidade pontual de se reduzir os riscos de morte na gestação e no primeiro ano de 
vida de uma criança. Além disto, pode-se inferir que políticas públicas mais focadas podem ser mais facilmente avaliadas.

Questionou-se também ao Secretário sobre as possíveis razões do resultado encontrado para o Programa Urgência e Emergência e o indicador taxa de resolubilidade macrorregional. Em resposta, o entrevistado destacou que o indicador possui importantes ressalvas e particularidades:

Então realmente a relação do Saúde em Casa com esse indicador é pequenininha. A do PROHOSP tem que ser grande. A relação com o Programa Urgência tem que ser grande. Mas, pode-se fazer uma separação das regiões que a gente tem a Rede de Urgência e Emergência implantada. Porque, se eu considerar que nós estamos analisando esse indicador pro estado inteiro, e que, até o ano passado, apenas três macros das 13 tinham a Rede de Urgência efetivamente implantada... Então a tendência da Rede de Urgência e Emergência ter dotado as macrorregiões dessa capacidade de resolubilidade é muito pequena. Ainda, como parte da Rede de Urgência, há até a previsão do transporte aéreo. Porque, dependendo da complexidade, realmente o paciente tem que vir para Belo Horizonte. Então esse é um indicador que merece muitas ressalvas (Secretário Adjunto de Saúde da SES/MG).

Destarte, é possível que daqui a alguns anos, com a Rede de Urgência e Emergência implantada integralmente no estado, os resultados das correlações - se refeitos - apontem para uma associação coerente entre esse programa e o indicador taxa de resolubilidade macrorregional.

\section{Considerações finais}

Buscando atender ao objetivo central deste trabalho, o qual consistiu na verificação da relação entre o gasto nos programas estruturadores e os indicadores finalísticos da SES/MG, conclui-se que, de maneira geral, essas variáveis estão correlacionadas de maneira significativa. Os dois principais gestores responsáveis pela alocação de recursos, no âmbito do setor de saúde estadual, justificaram esses casos de correlação pela inserção dos indicadores na lógica do atual sistema de gestão, em que o planejamento e o monitoramento das políticas públicas enfatizam a materialização dos resultados priorizados pelo governo.

Três das correlações encontradas constataram-se não significativas: casos que poderiam guardar relação com o tamanho da série histórica disponível. Para as correlações consideradas significativas, em apenas um caso o valor encontrado contestou a relação esperada, suposta no momento de planejamento das intervenções. O motivo alegado para tal, a partir das entrevistas, foi a estruturação 
ainda incipiente do programa correlacionado. Considerou-se, portanto, necessária a realização de estudos futuros que analisem se, em um cenário de funcionamento pleno da referida política, a correlação entre essa e o indicador mostrar-se-ia coerente à vinculação concebida pela SES-MG.

A análise de regressão confirmou a associação entre as variáveis, para os casos que se comportaram conforme a hipótese deste trabalho. Todavia, ainda que as associações estatísticas encontradas sejam relevantes, os entrevistados apontaram uma influência indireta dos indicadores na alocação de recursos. De modo que novos estudos devem ser feitos no sentido de melhor compreender esse processo de alocação, que, em alguma medida, privilegia o desempenho no curto prazo, em detrimento dos indicadores.

Foi apreciado, ainda, que os entrevistados, no intento de justificarem as correlações aferidas, apontam alguns pressupostos:

a. no momento inicial da implementação das políticas, os indicadores estudados são utilizados como critérios norteadores da alocação dos recursos, sendo encarados como critérios para priorização;

b. com as políticas em fase de implantação, tem-se uma estrutura que condiciona diretamente a alocação de recursos, já que o esforço de implantação é sucedido de um comprometimento orçamentário associado à manutenção;

c. abandonada a fase de preparação para a implantação dos programas estruturadores, os indicadores finalísticos deixam de influir diretamente sobre a alocação de recursos, passando a contribuir enquanto inseridos num macroprocesso de Gestão para Resultados;

d. a pactuação de resultados, o monitoramento intensivo e o contínuo aprimoramento do modelo de Gestão para Resultados são fatores que permitem, no ponto de vista dos entrevistados, a associação entre os valores empregados nos programas estruturadores e os resultados finalísticos apurados;

e. ao longo do tempo, o amadurecimento das políticas públicas e o alcance progressivo de melhores resultados finalísticos depende da observância aos indicadores, para que esses norteiem o desenho de novas ações estratégicas.

Este estudo não pretendeu, ademais, oferecer conclusões definitivas sobre o tema, mas explicitar a natureza da correspondência entre as variáveis analisadas. Assim sendo, sinalizar em que medida o esforço de planejamento, gerenciamento e o montante de recursos aplicados, no âmbito desses programas, se relacionam ao comportamento dos indicadores prioritários na área da saúde, em Minas Gerais. 
No tocante às limitações, denota-se o tamanho das séries históricas, as quais compõem o recorte do período 2004-2013. Pesquisas futuras, que usufruam de um recorte temporal maior, poderiam fornecer inferências mais razoáveis sobre a relação estudada.

Outra limitação refere-se ao fato de que a materialização dos resultados finalísticos demanda investimentos por tempo indeterminado. Desse modo, é possível que a apuração positiva de um dos indicadores, nos dias de hoje, esteja calcada no dispêndio ocorrido há cinco anos, por exemplo. A relação ano a ano foi utilizada para constituir a hipótese deste trabalho, com base na rotina de gestão e monitoramento utilizada no Governo de Minas Gerais.

Por fim, ressalva-se, também, que as entrevistas realizadas ao final da pesquisa, no intuito de embasar a análise qualitativa das correlações, assinalam perspectivas subjetivas, de cada um dos entrevistados. Pesquisas futuras poderiam ampliar o leque de políticas setoriais ou de entrevistados, de modo a contribuir para o entendimento da relação entre as despesas governamentais e os resultados das diversas áreas de governo. Dessa forma, seria possível verificar, ainda, se o aumento do gasto em saúde correlaciona-se de forma mais ou menos intensa à melhoria dos resultados da área, em comparação à mesma relação na segurança pública ou na área de educação, por exemplo.

\section{Referências bibliográficas}

Bonnefoy, Juan; ARMiJo, Marianela. Indicadores de desempeño en el sector público. Santiago do Chile: Ilpes, Cepal, 2005.

BRASIL. Ministério da Saúde. Secretaria de Vigilância em Saúde. Departamento de Análise de Situação de Saúde. Coordenação Geral de Informação e Análise Epidemiológica. Manual de vigilância do óbito infantil e fetal e do comitê de prevenção do óbito infantil e fetal. Brasília, 2009. Disponível em: <http://portal. saude.gov.br/portal/arquivos/pdf/Manual_Infantil_Fetal.pdf>. Acesso em $10 \mathrm{de}$ janeiro de 2014.

Brasil. Ministério da Saúde. Datasus. Fichas de indicadores: mortalidade infantil. Brasília, 2010. Disponível em:<http://www.ripsa.org.br/fichasIDB/record. php?node=a.11\&lang=pt\&version=ed5>. Acesso em 01 de fevereiro de 2014 .

CORRÊA, Izabela Moreira. Planejamento estratégico e gestão pública por resultados no processo de reforma administrativa do Estado de Minas Gerais. Revista de Administração Pública (RAP), Fundação Getúlio Vargas, Rio de Janeiro, 2007.

DANCEY, Christine P.; REIDY, John. Estatística sem matemática para Psicologia: usando SPSS para Windows. 3. ed. Porto Alegre: Artmed, 2006.

FONSECA, Jaime Raúl Seixas. Os métodos quantitativos na sociologia: dificuldades de uma metodologia de investigação. In: CONGRESSO PORTUGUÊS DE SOCIOLOGIA: MUNDOS SOCIAIS: SABERES E PRÁTICAS, 6., 2008, Lisboa. Anais... Lisboa, 2008. 
Fundação Oswaldo Cruz (FIOCRUz). Portal sobre Determinantes Sociais da Saúde (DSS). Atenção pré-natal no Brasil: uma questão de oferta, de acesso ou de escolaridade materna? Rio de Janeiro, 2012. Disponível em: <http://dssbr.org/ site/2012/05/atencao-pre-natal-no-brasil-uma-questao-de-oferta-de-acesso-oude-escolaridade-materna/>. Acesso em 17 de abril de 2013.

GUIMARÃES, Tadeu Barreto; CAMPOS, Eder Sá Alves. Programa Estado para Resultados: balanço da implementação de um escritório de apoio à gestão estratégica e gestão por resultados em Minas Gerais. In: Congresso ConSAD, 2., 2009 Brasília. Anais... Brasília, 2009.

JANNuzzı, Paulo de Martino. Indicadores sociais na avaliação e formulação de políticas. Revista Brasileira de Administração Pública, Rio de Janeiro, v.36, 2002. Acesso em: 20 de janeiro de 2013. Disponível em: <http://www.cedeps.com.br/wpcontent/uploads/2011/02/INDICADORES-SOCIAIS-JANUZZI.pdf>.

JANNuzzI, Paulo de Martino et al. Estruturas de sistemas de monitoramento e especificação de pesquisas de avaliação, os problemas dos programas públicos no Brasil são. Caderno EIAPP, Reflexões para Ibero-América. Brasília: Enap, 2009.

LÉLIS, Leandro José Barros. Indicador de resolubilidade como instrumento de avaliação da regionalização da assistência à saúde no SUS/MG. In: CONGRESSO DE Gestão PúbliCA do ConSAD, 5., 2012, Brasília. Anais... Brasília, 2012.

LUCENA, Romualdo Mendonça de; SouSA, Jailson Lopes de. Anos potenciais de vida perdidos (APVP) por Aids: Pernambuco, 1996 e 2005. DST - Jornal Brasileiro de Doenças Sexualmente Transmissíveis, v. 21, n. 3, 2009. Acesso em 28 de março de 2013. Disponível em: < http://www.dst.uff.br/revista21-3-2009/7-Anos-Potenciaisde-Vida.pdf>.

MACKAY, Keith. Cómo crear sistemas de SyE que contribuyen a um buengobierno. Washington, DC: Banco Mundial, 2008.

MALACHIAS, I. et al. A resolubilidade e os vazios da assistência hospitalar micro e macrorregional do SUS/MG em 2010 e a evolução - 2003/2010. Belo Horizonte: Secretaria de Estado de Saúde de Minas Gerais, 2010.

Marconi, M. A.; LaKatos, E. M. Metodologia do trabalho científico. 5 ed. São Paulo: Atlas, 2001.

Minas Gerals. Constituição Estadual de 1989. 11 ed. Belo Horizonte: Assembleia Legislativa de Minas Gerais, 1989.

Minas GeraIs. Secretaria de Estado de Planejamento e Gestão. Plano Mineiro de Desenvolvimento Integrado (PMDI) 2003-2020. Belo Horizonte, 2003.

MinAs GeraIs. Secretaria de Estado de Planejamento e Gestão. Plano Plurianual de Ação Governamental 2004-2007. Volume I. Belo Horizonte, 2004.

Minas GeraIS. Secretaria de Estado de Planejamento e Gestão. Plano Mineiro de Desenvolvimento Integrado (PMDI) 2007-2023. Belo Horizonte, 2007.

MinAs GeraIS. Secretaria de Estado de Planejamento e Gestão. Plano Plurianual de Ação Governamental 2008-2011. Belo Horizonte, 2008a.

MinAs GeraIS. Secretaria de Estado de Planejamento e Gestão. Plano de Programa Saúde em Casa. Belo Horizonte, 2008b. 
Minas Gerais. Escritório de Prioridades Estratégicas. Caderno de Indicadores 2011. Belo Horizonte, 2011a.

Minas GeraIS. Secretaria de Estado de Planejamento e Gestão. Plano Mineiro de Desenvolvimento Integrado (PMDI) 2011-2030. Belo Horizonte, 2011b.

MinAs GeraIS. Secretaria de Estado de Planejamento e Gestão. Ficha de Processo Gestão do Atendimento de Urgências e Emergências no Estado. Belo Horizonte, 2012a.

Minas GeraIs. Secretaria de Estado de Planejamento e Gestão. Ficha de Processo de Manutenção e Incentivo às Equipes de Atenção Primária à Saúde. Belo Horizonte, 2012b.

MinAs GeraIs. Secretaria de Estado de Planejamento e Gestão. Plano Plurianual de Ação Governamental 2012-2015. Belo Horizonte, 2012c.

MinAs GeraIS. Secretaria de Estado de Planejamento e Gestão. Plano de Programa Saúde em Casa. Belo Horizonte, 2012d.

Minas Gerals. Secretaria de Estado de Planejamento e Gestão. Plano de Projeto Ampliação da Estrutura de Atenção Primária à Saúde. Belo Horizonte, 2012e.

Minas Gerals. Secretaria de Estado de Planejamento e Gestão. Plano de Projeto Rede de Urgência e Emergência. Belo Horizonte, $2012 \mathrm{f}$.

Minas GeraIs. Secretaria de Estado de Planejamento e Gestão. Plano de Projeto Rede de Viva Vida/Mães de Minas. Belo Horizonte, 2012g.

Minas Gerais. Escritório de Prioridades Estratégicas. Caderno de Indicadores 2014. Belo Horizonte, 2014.

Moreno, Mauricio. Módulo 6: Seguimiento y evaluación de los resultados. Gestión para resultados en el desarrollo em gobiernos subnacionales. BID, 2011.

MoresI, Eduardo. Metodologia da Pesquisa. Brasília: UCB, 2003. Acesso em 15 de maio de 2013. Disponível em <http://www.unisc.br/portal/upload/com_arquivo/ metodologia_da_pesquisa..pdf $>$.

PeIXoto, Heloisa Côrtes Gallotti; SouzA, Maria de Lourdes de. O indicador anos potenciais de vida perdidos e a ordenação das causas de morte em Santa Catarina, 1995. Inf. Epidemiol. Sus, Brasília, v. 8, n. 1, mar. 1999. Disponível em <http://scielo. iec.pa.gov.br/scielo.php?script=sci_arttext\&pid=S0104-16731999000100003\&In $\mathrm{g}=\mathrm{pt \& nrm}=\mathrm{iso}>$. Acessos em 29 maio 2013. http://dx.doi.org/10.5123/S010416731999000100003 . Acesso em 10 de maio de 2013.

PFEIFFER, Peter. O Quadro Lógico: um método para planejar e gerenciar mudanças. In: Giacomoni, James; PAgnuSSAT, José Luiz. Planejamento e Orçamento Governamental. Brasília: Enap, 2006. Coletânia, v. 1, p. 145-190.

Programa das nações Unidas para o Desenvolvimento (PNUD). Publicações: esperança de vida ao nascer. S.I., s.d. Acesso em 02 de maio de 2013. Disponível em: <http://www.pnud.org.br/publicacoes/atlas_bh/release_longevidade.pdf>.

SerRA, Alberto; FigueroA, Verónica; SAZ, Ángel. Modelo aberto de gestão para resultados no setor público. [Modelo abierto de gestión para resultados em elsector público]. Traduzido por: Ernesto Montes-Bradley y Estayes. Natal: SEARH/RN, 2008. 
WERNECK, C. et al. A utilização de indicadores na administração pública: contribuições do governo mineiro para a atividade de monitoramento. In.: GUIMARÃES, T. B.; Pordeus, I. A.; CAMPOS, E. S. A. (Orgs.). Estado para resultados: avanços no monitoramento e avaliação da gestão pública em Minas Gerais. Belo Horizonte: Editora UFMG, 2010.

Geovana Maria Carmo Santos

É Especialista em Gestão de Projetos pela Pontifícia Universidade Católica (PUC Minas).

Contato: geo_msantos@yahoo.com.br

Mauro César da Silveira

Possui Douturado em Administração de Empresas pela Universidade Federal de Minas Gerais (UFMG).

Contato: maurocsilveira@hotmail.com

Andre Correa de Oliveira

Graduando em Administração Pública pela Fundação João Pinheiro.

Contato: andre.coliveira3@gmail.com 
